\title{
Plasma Lipoproteins in Liver Disease: I. Immunologically Distinct Low-Density Lipoproteins in Patients with Biliary Obstruction *
}

\author{
Sam Switzer † with the technical assistance of Lila Satenstein \\ (From the Department of Medicine, Albert Einstein College of Medicine and the Albert \\ Einstein College Hospital; the Unit for Research in Ageing, and the Bronx \\ Municipal Hospital Center, Bronx, New York)
}

\begin{abstract}
Sera from patients with extrahepatic biliary obstruction were found to have an abnormal lipoprotein (obstructive lipoprotein) which failed to react with antibodies to normal lipoproteins of $d<1.063$. Preparations of this abnormal lipoprotein made by a combination of immunoprecipitation and multiple polyanion precipitations revealed a high content of free cholesterol $(26 \%)$ and phospholipids $(61 \%)$ but only trace amounts of cholesterol esters and triglycerides. Protein content varied from $13 \%$ to a corrected low of $5 \%$ when ultracentrifugation was also performed. Amino acid analyses of the latter preparations resembled that of lipoproteins of $d<1.006$.

The reasons underlying the apparent unreactivity of the abnormal lipoprotein were explored. No evidence could be found for soluble antigen-antibody complexes of $\gamma$-globulin and the abnormal lipoprotein, nor for inhibition of antigen-antibody complex formation by serum factors. Purified preparations of obstructive lipoprotein did not react with antisera to high- or low-density lipoproteins prepared from normal sera. Moreover, rabbits immunized with the abnormal lipoproteins produced specific antibodies to this lipoprotein which reacted with a $\mathrm{d}<1.006$ lipoprotein in normal sera. All other lipoprotein fractions from normal sera were unreactive. It is not known whether this lipoprotein is abnormal by virtue of the presence of a unique peptide or because of secondary alterations in lipoprotein structure.
\end{abstract}

\section{Introduction}

The marked elevation of serum cholesterol that follows obstruction of the biliary system (1) is due to an increase of lipoproteins of $d$ 1.019-1.063 (2, $3)$. Previous studies have suggested that these

* Received for publication 6 December 1966 and in revised form 19 May 1967.

This work was initiated under U. S. Public Health Service Training Grant HE-05273, and was performed in part while a Career Investigator, I-496, of the Health Research Council of the City of New York. Supported by Public Health Service Grants HE-02965, HD 00674, AM 11538, and FR-50.

† Deceased, 4 June 1967.

Address requests for reprints to Dr. Howard A. Eder, Department of Medicine, The Albert Einstein College of Medicine, Yeshiva University, Eastchester Road \& Morris Park Avenue, Bronx, N. Y. 10461. lipoproteins are not merely increased in amount but are possibly abnormal (2). In 1956, Russ and coworkers (4) isolated a low-density lipoprotein, which was unique in that all of the cholesterol was in the nonesterified form, from the serum of a patient with biliary cirrhosis. In addition, it was noted, but without details, that this lipoprotein did not react with specific antisera directed against normal $\mathrm{d}<1.063$ lipoproteins.

The current study was undertaken in order to more clearly define this abnormal lipoprotein. The data presented here demonstrate that in the presence of biliary obstruction, sera may contain considerable amounts of $\mathrm{d}<1.063$ lipoproteins which are unreactive to antisera known to react with all normal lipoproteins. This property provides the basis for methods that have been developed to mea- 
sure and isolate the abnormal lipoproteins. A preliminary characterization of this lipoprotein isolated by immunologic means is included. For brevity's sake, we will refer to this lipoprotein as the "obstruction-lipoprotein" (OLP).

\section{Methods}

Lipoproteins. Preparative ultracentrifugation was performed by the method of Havel, Eder, and Bragdon (5) in which solvent density was raised by the addition of solutions of potassium bromide and sodium chloride. Solutions of $\mathrm{d} 1.21$ were ultracentrifuged at $114,000 \mathrm{~g}$ in a 40.3 rotor for $40 \mathrm{hr}$; at other densities, ultracentrifugation was performed for $16-24 \mathrm{hr}$. Polyanion precipitation of $d<1.063$ lipoproteins was accomplished by the method of Burstein and Samaille (6) in which 20 parts serum or $d>1.006$ serum proteins were mixed with one part of a $10 \%$ solution of mepesulfate ${ }^{1}$ (the sodium salt of sulfated polygalacturonic acid-methyl ester-methyl glycoside) and two parts of $1 \mathrm{M} \mathrm{CaCl}_{2}$. The precipitate was dissolved by dropwise addition of $5 \%$ sodium chloride. For further purification, this solution was diluted with 9 volumes of distilled water and $\mathrm{d}<1.063$ lipoproteins reprecipitated by the addition of 1 volume of $1 \mathrm{M} \mathrm{CaCl}_{2}$. The latter steps were repeated three times. To remove the polyanion, the precipitate was dissolved in $\mathrm{d} 1.063$ $\mathrm{KBr}-\mathrm{NaCl}$ solution and ultracentrifuged. The final product was dialyzed against isotonic saline to remove $\mathrm{KBr}$.

Turbidometric estimation of $\mathrm{d}<1.063$ lipoproteins was performed, essentially according to the method of Burstein and Samaille (7) as follows : to $0.2 \mathrm{ml}$ of human serum diluted in a $10 \times 75 \mathrm{~mm}$ cuvette containing $2.0 \mathrm{ml}$ of $0.025 \mathrm{M} \mathrm{CaCl}_{2}, 0.05 \mathrm{ml}$ of $5 \%$ heparin (USP) was added. The tubes were mixed and after $4 \mathrm{~min}$ the optical density was read at $700 \mathrm{~m} \mu$. Values were expressed as the difference between the optical density readings before and after heparin multiplied by 1000 . For sera containing more than 500 turbidometric units of these lipoproteins, aliquots of $0.1 \mathrm{ml}$, or less, were added. A normal value for fasted human subjects is considered to be $200-300$ turbidity units. To demonstrate the relationship of lipoprotein concentration to the turbidity generated, a standard curve was constructed in the following manner. Increasing aliquots of dialyzed $\mathrm{d}<1.063$ lipoproteins from a normal subject were diluted in a solution of $2 \%$ albumin in isotonic saline and assayed by this method. A linear relationship was obtained from $0-500$ turbidity units.

Preparation of antisera. Normal serum lipoproteins were prepared for immunization injections by repeated precipitation with mepesulfate, subsequent ultracentrifugation at $\mathrm{d} 1.063$ to sediment and remove the mepesulfate, and finally dialysis against $0.8 \% \mathrm{NaCl}$ solution containing $0.1 \%$ EDTA. At least $1 \mathrm{mg}$ of protein was used for each immunization (8). The first injection was prepared by emulsifying the aqueous solution of lipoprotein

\footnotetext{
${ }^{1}$ Hoffmann-La Roche, Inc., Nutley, N. J.
}

(antigen) with an equal volume of complete Freund's adjuvant and this was injected in divided doses into the footpads of rabbits or the axillae of goats. 2 and $4 \mathrm{wk}$ later a similar preparation was made by emulsifying freshly frozen, thawed antigen with incomplete Freund's adjuvant and was injected in divided doses into the four quadrants of the back. 1-2 wk later, the animals were bled. Booster injections of lipoprotein without adjuvant were given as indicated. As determined by immunoelectrophoresis and gel diffusion, the goat antiserum reacted with $\mathrm{d}$ 1.006-1.063 lipoproteins and with $\mathrm{d}<$ 1.006 lipoproteins, but not with proteins or lipoproteins of d $>1.063$.

Fresh goat antiserum was mixed with 3 volumes of $0.5 \%$ Rivanol 2 (ethoxydiamino acridine lactate) in 0.05 м Tris buffer, $\mathrm{pH} 8.2$ (9). The precipitate was removed by centrifugation and the supernatant containing the goat $\gamma$-globulin was mixed with dry sodium chloride, $5 \mathrm{~g} / 100$ ml. After $16 \mathrm{hr}$ at $4^{\circ} \mathrm{C}$ the resulting precipitate of $\mathrm{Ri}$ vanol was removed by centrifugation. The supernatant at $\mathrm{pH} 7.0$ was mixed with dry ammonium sulfate, 28 $\mathrm{g} / 100 \mathrm{ml}$, and centrifuged at $5-10^{\circ} \mathrm{C}$ until precipitation was complete. The $\gamma$-globulin precipitate was dialyzed to remove ammonium sulfate; sodium azide, $1 \mathrm{mg} / \mathrm{ml}$, was added as a preservative. When indicated, solutions were concentrated to a protein content of at least 20 $\mathrm{mg} / \mathrm{ml}$ by vacuum dialysis in a collodion finger.

$\gamma$-Globulin preparations were titrated, to determine their biological potency, with representative sera from subjects without liver disease. Solutions of globulin and sera were mixed in varying proportions and, after $15 \mathrm{~min}$ at room temperature, centrifuged at $2000 \mathrm{rpm}$ for $15 \mathrm{~min}$. The $\mathrm{d}<1.063$ lipoproteins remaining in the supernatant were measured by the turbidometric method or recovered by polyanion precipitation and analyzed chemically. The antigen-antibody precipitate was washed three times with $0.9 \%$ saline, dissolved in $1 \mathrm{~N} \mathrm{NaOH}$, and the protein content determined. It was noted that when insufficient antibody was present the supernatant remained grossly turbid after centrifugation, but beyond the equivalence point a clear supernatant was obtained.

OLP was prepared from sera of individual patients with biliary obstruction by initial immunoprecipitation of reactive low-density lipoproteins with the $\gamma$-globulin solution. The reactive $d<1.063$ lipoproteins were precipitated and a clear supernatant obtained when antibody was present in excess. The unreactive lipoproteins of $\mathrm{d}<1.063$ were recovered from the supernatant by precipitation with mepesulfate (seen above) and were washed three times by reprecipitation. The precipitates were dissolved in salt solutions of $\mathrm{d} 1.063$ and ultracentrifugation was performed. For the preparation of OLP antigens, additional ultracentrifugation and washing at d 1.006 were carried out. Rabbits were immunized with aliquots of these lipoprotein preparations, as described above. The resulting antisera were absorbed with supernatants from mepesulfate precipitation of $2 \mathrm{ml}$ of normal serum. This supernatant was first dialyzed and then lyophilyzed and $2 \mathrm{ml}$ of the antiserum was added

\footnotetext{
${ }^{2} \mathrm{~K}$, and $\mathrm{K}$. Laboratories, Jamaica, N. Y.
} 
to it. This mixture was incubated at $37^{\circ} \mathrm{C}$ for $45 \mathrm{~min}$ and the immunoprecipitate was removed by centrifugation at $2000 \mathrm{rpm}$ for $60 \mathrm{~min}$ at $5-10^{\circ} \mathrm{C}$.

Antisera were also obtained from commercial sources. ${ }^{3}$

Immunodiffusion studies. Immunoelectrophoresis was performed by the method of Scheidegger (10) in a $1 \%$ gel with $0.04 \mathrm{M}$ barbital buffer, $\mathrm{pH}$ 8.2. Agarose ${ }^{4}$ was substituted for agar as suggested by Burstein and Fine (11). Double diffusion studies were performed in sealed Petri dishes using the same preparation of gel. After diffusion in air at room temperature for 1-3 days, slides and plates were photographed against a black background with oblique light from below (dark field). Unreacted proteins were removed by immersion in $0.9 \% \mathrm{NaCl}$ for 3-7 days. The slides were covered with a piece of filter paper and dried at $80^{\circ} \mathrm{C}$, then stained for protein with Naphthol Blue-black 5 or for lipid with Oil Red O.5

Labeling with ${ }^{125} I$ (12). The $\gamma$-globulin prepared from the goat antiserum was iodinated immediately before use. To a test tube, $13 \times 100 \mathrm{~mm}$, were added in order : 0.05 $\mathrm{ml}$ of $0.01 \mathrm{M} \mathrm{KI} ;{ }^{120} \mathrm{I}^{6}$ in $0.1 \mathrm{~N} \mathrm{NaOH} ; 0.2 \mathrm{ml}$ of $2.5 \mathrm{~N}$ $\mathrm{HCl} ; 0.05 \mathrm{ml}$ of $1 \mathrm{M} \mathrm{NaNO}$; and $0.2 \mathrm{ml}$ of $2.5 \mathrm{~N} \mathrm{NaOH}$. The contents were mixed, adjusted to $\mathrm{pH} 8.1$, and added rapidly with constant stirring to a solution of the $\gamma$-globulin, containing $20-30 \mathrm{mg} / \mathrm{ml}$ protein, which had been dialyzed previously for $2 \mathrm{hr}$ against $0.17 \mathrm{~m}$ sodium borate buffer at $\mathrm{pH} 8.1$. The mixture was allowed to stand at room temperature for $20 \mathrm{~min}$. Unbound ${ }^{125} \mathrm{I}$ was then removed by filtration through Sephadex ${ }^{7}$ G-25 in $0.9 \%$ $\mathrm{NaCl}$ solution. By this method the efficiency of incorporation was $20-30 \%$ and an average of 1-2 atoms of iodine were incorporated per molecule of $\boldsymbol{\gamma}$-globulin.

Chromatographic techniques. Thin-layer chromatography was performed by methods described by Mangold (13) with modifications as noted in our previous work (14). Gel filtration of proteins was performed on a column, $4 \times 52 \mathrm{~cm}$, containing Sephadex ? G-200 (15) equilibrated with buffered saline containing $0.075 \mathrm{M}$ $\mathrm{NaCl}$ and $0.075 \mathrm{M}$ Tris buffer, $\mathrm{pH}$ 7.65.

Amino acid analysis. For amino acid analysis, we prepared lipoprotein fractions using the conditions of ultracentrifugation as previously described. Lipoproteins $\mathrm{d}<1.006$ were prepared by ultracentrifugation of serum which had been layered under an equal volume of $0.9 \%$ $\mathrm{NaCl}$. After ultracentrifugation the lipoproteins in the topmost centimeter of the tube were removed and again subjected to ultracentrifugation. The remaining lowdensity lipoproteins $(d>1.006)$ were recovered from the $\mathrm{d}>1.006$ fraction by polyanion precipitation, reprecipitated three times, dissolved in $\mathrm{d} 1.063 \mathrm{KBr}$ and $\mathrm{NaCl}$

${ }^{3}$ Goat anti-whole human serum, goat anti-human $\beta \mathrm{LP}$, and rabbit anti-goat $\boldsymbol{\gamma}$-globulin were obtained from Hyland Laboratories, Los Angeles, Calif.; rabbit antihuman $\beta \mathrm{LP}$ and rabbit anti-human $\alpha_{1} \mathrm{LP}$, from Behringwerke AG, Lloyd Brothers, Inc., Cincinnati, Ohio.

4 Bausch and Lomb Incorporated, Rochester, N. Y.

5 Allied Chemical Corp., New York, N. Y.

${ }^{6}$ New England Nuclear Corporation, Boston, Mass.

7 Pharmacia Fine Chemicals Inc., New Market, N. J. solution, collected by ultracentrifugal flotation and dialyzed against $0.9 \% \mathrm{NaCl}$. The serum proteins remaining in the supernatant after polyanion precipitation were adjusted to d 1.063 with $\mathrm{KBr}$ and $\mathrm{NaCl}$ solutions and ultracentrifuged to remove (by flotation) any traces of $\mathrm{d}<1.063$ lipoproteins. The $\mathrm{d}>1.063$ fraction was adjusted to $\mathrm{d} 1.21$ with solid $\mathrm{KBr}$ and subjected to ultracentrifugation. The $\mathrm{d} 1.063-1.21$ lipoproteins in the topmost centimeter of the tube were removed, again subjected to ultracentrifugation, and then dialyzed. To prepare the OLP, sera were treated as noted above, with the addition of a step after removal of the $d<1.006$ lipoproteins. The $d>1.006$ lipoproteins were reacted with the goat $\boldsymbol{\gamma}$-globulin prepared from antiserum to normal $\mathrm{d}<$ 1.063 lipoproteins, in order to precipitate reactive lipoproteins of $\mathrm{d}<1.063$.

Lipoproteins in $0.9 \% \mathrm{NaCl}$ were extracted with 20 volumes of isopropanol at room temperature for at least 20 hr. After centrifugation and removal of the isopropanol, the precipitate was washed three times with ethyl ether, briefly air-dried, and then hydrolyzed in $6 \mathrm{M} \mathrm{HCl}$ in a sealed glass ampule at $105^{\circ} \mathrm{C}$ for $22 \mathrm{hr}$. Excess $\mathrm{HCl}$ was then removed by evaporation under vacuum. Amino acids were determined by chromatography on IR 120 by the method of Spackman et al. (16).

\section{Analytical Methods}

Lipids were extracted by the method of Folch et al. (17). Lipid phosphorus was determined according to the method of Beveridge and Johnson (18), triglycerides by the method of Van Handel (19), conjugated bile acids by the method of Carey (20), and protein by the method of Lowry et al. (21). Early in the study total cholesterol was determined by the method of Abell et al. (22) and free cholesterol by the method of Sperry and Webb (23) ; later these determinations were performed using the ferric chloride method as described by Leffler (24).

\section{Patients}

Patients with surgically proven, complete biliary obstruction on the medical, pediatric, and surgical services of the Bronx Municipal Hospital Center and the Hospital of the Albert Einstein College of Medicine were studied. Diagnoses included extrahepatic obstruction due to carcinoma, cholethiasis of the common bile duct, ligation of the common bile duct, congenital biliary atresia, and occlusion of an indwelling $\mathrm{T}$-tube in a patient with sclerosing cholangitis. Sera for control studies were obtained from normal, healthy volunteers and patients GRI and AM with familial hypercholesterolemia who were otherwise in good health.

\section{Results}

Detection of immunologically unreactive lipoproteins of $d<1.063$

Quantitative immunoprecipitation studies were performed using the $\gamma$-globulin prepared from anti- 


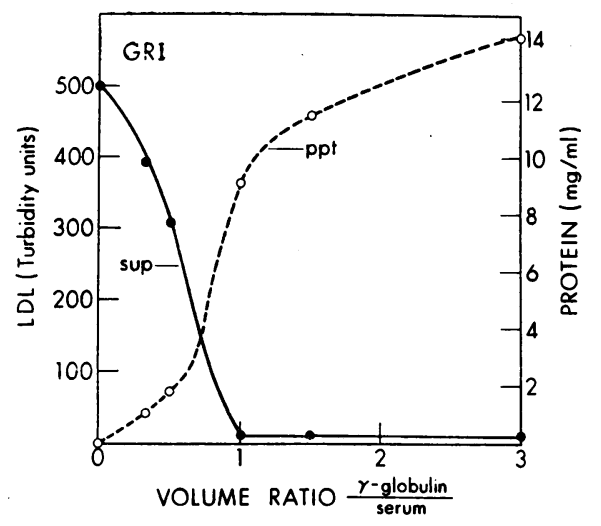

Fig. 1. Quantitative Immunoprecipitation of $\mathrm{D}<$ 1.063 LIPOPROTEINS FROM THE SERUM OF PATIENT GRI WITH FAMILIAL HYPERCHOLESTEROLEMIA. The patient's serum was treated with increments of $\gamma$-globulin solution prepared from antiserum to normal $\mathrm{d}<1.063$ lipoproteins. The amount of protein in the immunoprecipitate $(p p t)(0--0)$ and the lipoprotein remaining in the supernatant $(s u p)(0-0)$ are plotted against the ratio of the volume of $\gamma$-globulin solution to serum. LDL, lowdensity lipoproteins.

serum to $d<1.063$ lipoproteins prepared from fasting normal subjects. Titration of sera from subjects free of liver disease demonstrated only negligible amounts of $d<1.063$ lipoproteins unreactive to the $\gamma$-globulin (Fig. 1). The slope of the titration curves for normal sera varied according to the biologic potency of the particular lot of $\gamma$-globulin used in the assay. At the end point of the titration very little additional lipoprotein was precipitated. There was an abrupt clearing of the supernatant. Similar titrations were performed on sera from patients with biliary obstruction; these sera were found to contain large amounts of nonprecipitable lipoproteins of $\mathrm{d}<$ 1.063. Indeed, in the example shown in Fig. 2, approximately $65 \%$ of the $\mathrm{d}<1.063$ lipoprotein from patient RM's serum remained in solution. (It will be seen later, in Table I, that this represented $75 \%$ of the cholesterol and $81 \%$ of the phospholipid in the serum $\mathrm{d}<1.063$ fractions.)

The completeness of the immunoprecipitation was demonstrated by immunoelectrophoresis of sera before and after immunoprecipitation (Fig. 3, left), using a commercial antiserum to $d<1.063$ lipoproteins in the trough. Similarly, double diffusion studies with a large number of samples of serum subjected to immunoprecipitation showed that there had been removal of reactive $d<1.063$ lipoproteins in every instance. To demonstrate the normal reactivity of other serum proteins under these conditions, serum before and after immunoprecipitation was subjected to electrophoresis with antiserum to whole serum present in the trough (Fig. 3, right).

\section{Composition of the unreactive lipoproteins of $d<1.063$}

To compare the lipid composition of the reactive and unreactive $d<1.063$ lipoproteins, an experiment was performed in which sera were subjected to immunoprecipitation with the $\gamma$-globulin prepared against normal $\mathrm{d}<1.063$ lipoproteins. The unreactive $d<1.063$ fraction was isolated, washed, and analyzed for lipids; the antigen-antibody complex was similarly treated (Table I). In each of these sera the major portion of the serum cholesterol was in the unreactive fraction. However, the level of cholesterol in the reactive fraction is comparable with the amounts that would be precipitated from normal serum. The unreactive fraction contained $96-100 \%$ free cholesterol, as compared with a mean of $47 \%$ free cholesterol in the reactive fraction. As judged by the cholesterol-phospholipid ratio the unreactive fraction was consistently richer in phospholipid than the reactive fraction. Thin-layer chromatography indicated a virtual absence of triglyceride in the unreactive fraction.

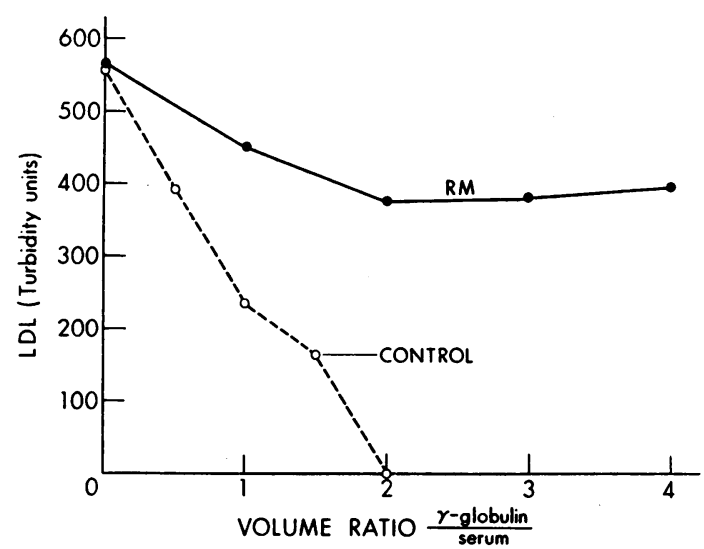

Fig. 2. Quantitative immunoprecipitation oF SERUM FROM CONTROL SUBJECT AND FROM PATIENT RM WITH EXTRAHEPATIC BILIARY OBSTRUCTION DUE TO LIGATION OF THE COMMON BILE DUCT. The titration was carried out as in Fig. 1. 


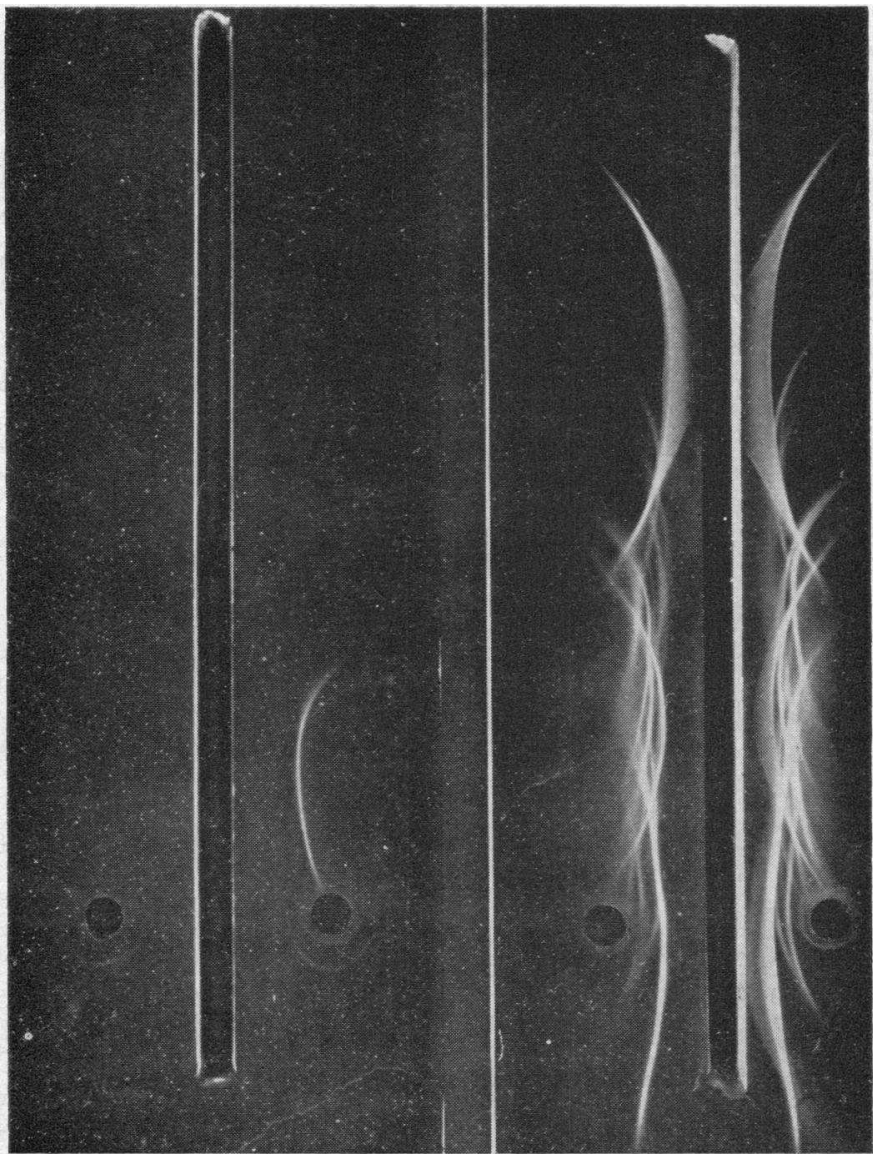

Fig. 3. IMMUNOELECTROPHORESIS OF SERUM FROM PATIENT ROG WITH EXTRAHEPATIC BILIARY OBSTRUCTION DUE TO CARCINOMA, BEFORE AND AFTER IMMUNOPRECIPITATION OF LIPOPROTEIN WITH $\gamma$-GLOBULIN SOLUTIONS PREPARED FROM ANTISERUM TO NORMAL D $<$ 1.063 LIPOPROTEINS. On the left side of each slide is treated serum and on the right untreated serum. From left to right, the troughs contain goat anti $\beta$-lipoprotein (Hyland) and goat antiwhole human serum (Hyland). The whole serum contained 509 $\mathrm{mg}$ of cholesterol/100 $\mathrm{ml}$ and the treated serum $392 \mathrm{mg}$ of cholesterol $/ 100 \mathrm{ml}$.

The protein content of the unreactive fraction varied from an average of $13 \%$ in the preparations to a low of $5 \%$ in lots produced by more elaborate procedures, including ultracentrifugation. This is considerably less than has been reported for normal d 1.006-1.063 lipoproteins (25), but greater than that reported by Russ et al. (4) for their abnormal lipoprotein.

The nature of the nonreactivity of the OLP

The inability of $\mathrm{d}<1.063$ lipoproteins, in the sera of patients with biliary obstruction, to precipitate with antibody to $\mathrm{d}<1.063$ lipoproteins from normal subjects may be explained by the following hypotheses: $(a)$ the antigen and antibody have reacted, but have formed a soluble complex rather than a precipitate, $(b)$ reaction is prevented by the interference of some serum factor, $(c)$ the antigenic site is present but inaccessible to the antibody, and $(d)$ the antigenic determinant present in normal $\mathrm{d}<1.063$ lipoproteins is absent. These possibilities were investigated.

Sera from patients with and without biliary obstruction were subjected to the usual immunoprecipitation and the supernatants were subjected to double diffusion in gel against antiserum prepared 
TABLE I

Composition of $d<1.063$ lipoproteins in sera of patients* with biliary obstruction

\begin{tabular}{|c|c|c|c|c|c|}
\hline & Cholesterol & Phospholipid & Protein & $\frac{\text { Free cholesterol }}{\text { Total cholesterol }}$ & $\frac{\text { Cholesterol }}{\text { Phospholipid }}$ \\
\hline Unreactive lipoprotein & & $m g / 100 \mathrm{ml}$ & & & \\
\hline $\begin{array}{l}\text { HG } \\
\text { RM } \\
\mathrm{D}^{\prime} \mathrm{An} \\
\text { Rog } \\
\text { Mean }\end{array}$ & $\begin{array}{l}184 \\
471 \\
275 \\
392 \\
331\end{array}$ & $\begin{array}{r}405 \\
1174 \\
658 \\
915 \\
788\end{array}$ & $\begin{array}{l}107 \\
222 \\
137 \\
240 \\
177\end{array}$ & $\begin{array}{l}0.96 \\
0.96 \\
1.00 \\
1.00 \\
0.98\end{array}$ & $\begin{array}{l}0.45 \\
0.40 \\
0.42 \\
0.43 \\
0.43\end{array}$ \\
\hline $\begin{array}{l}\text { Reactive lipoprotein } \\
\text { HG } \\
\text { RM } \\
\text { D'An } \\
\text { Rog } \\
\text { Mean }\end{array}$ & $\begin{array}{l}140 \\
157 \\
149 \\
117 \\
141\end{array}$ & $\begin{array}{l}195 \\
267 \\
255 \\
243 \\
240\end{array}$ & $\begin{array}{l}\text { E } \\
\text { - }\end{array}$ & $\begin{array}{l}0.41 \\
0.44 \\
0.48 \\
0.55 \\
0.47\end{array}$ & $\begin{array}{l}0.72 \\
0.59 \\
0.58 \\
0.48 \\
0.59\end{array}$ \\
\hline
\end{tabular}

* Patient RM had extrahepatic biliary obstruction due to ligation of the common bile duct, whereas HG, D'An, and Rog had obstruction due to carcinoma.

in rabbits to goat $\gamma$-globulin. A precipitin band to $\gamma$-globulin was formed. It was hypothesized that the reaction band formed by a soluble complex might differ from that of $\gamma$-globulin alone because of altered electrophoretic mobility or slower diffusion or both. Thus, a second reaction band might be found when sera containing OLP is compared with normal serum in this manner. A second reaction band was not found nor was the usual reaction band altered.

To further test the possible formation of a soluble complex, an experiment was performed in which the $\gamma$-globulin used to separate reactive and unreactive $\mathrm{d}<1.063$ lipoproteins was labeled with ${ }^{125} \mathrm{I}$ and the fractions subsequently isolated were

\section{TABLE II}

Components isolated in $d<1.063$ lipoprotein fractions after reaction with goat $\gamma$-globulin-125I (Specific activity $=$ $107,800 \mathrm{cpm} / \mathrm{mg}$ ) containing specific antibodies to humand $<1.063$ lipoproteins

\begin{tabular}{lrc}
\hline \hline & $\begin{array}{c}\text { Immunoreactive } \\
\text { lipoprotein }\end{array}$ & $\begin{array}{c}\text { Unreactive } \\
\text { lipoprotein }\end{array}$ \\
\hline (1) Radioactivity, $c p m$ & 43,510 & 3,624 \\
(2) Protein, $\mu g$ & 1,764 & 238 \\
(3) Cholesterol, $\mu g$ & 725 & 1,205 \\
(4) Goat $\gamma$-globulin, & 404 & 34 \\
(5) Human $\gamma$-globulin, & 77 & 34 \\
(6) Anti-LP antibody, & 327 & 0 \\
(7) LP apoprotein, $\mu g \|$ & 1,360 & 204 \\
\hline
\end{tabular}

$*(4)=1000 \times(1) / 107,800$.

$\ddagger$ Human $\gamma$-globulin-125I isolated in control experiment as described in the text.

$\S(6)=(4)$ minus $(5)$

$\|(7)=(2)$ minus $(4)$. analyzed for the presence of ${ }^{125} \mathrm{I} \gamma$-globulin. The precipitated fractions were washed exhaustively, 5 times, until negligible amounts of radioactivity could be removed. The results of this experiment are summarized in Table II. The lipoprotein $\gamma$-globulin complex representing the reactive fraction was shown to contain $1764 \mu \mathrm{g}$ of protein, of which $404 \mu \mathrm{g}$ could be attributed to $\gamma$-globulin on the basis of its content of radioactivity. The 404 $\mu \mathrm{g}$ of protein represented $23 \%$ of the total protein in the precipitate, and $8 \%$ of the total mass of the precipitate. On the other hand, the unreactive $\mathrm{d}<1.063$ lipoproteins isolated as a mepesulfate complex was shown to contain $238 \mu \mathrm{g}$ of protein, of which $34 \mu \mathrm{g}$ could be attributed to $\gamma$-globulin. In this instance, $34 \mu \mathrm{g}$ of protein represented $14 \%$ of the protein but only $0.6 \%$ of the total mass in the precipitate. Ultracentrifugation reduced these values to 11.5 and $0.5 \%$, respectively. This very low content of goat $\gamma$-globulin relative to the total mass of the precipitate (protein plus lipid) raised the possibility of nonspecific contamination. This was evaluated in a parallel experiment in which the reactive and unreactive fractions were first separated by use of unlabeled goat $\gamma$-globulin and then the two fractions were resuspended in ${ }^{125} \mathrm{I}$ labeled human $\gamma$-globulin devoid of specific antibody before proceeding with purification and isolation. Any label isolated in this circumstance would represent nonspecific contamination by human $\gamma$-globulin rather than a specific antibody bound to its corresponding antigen. It was found (Table II, line 5) that only one-fifth of the $\gamma$-glob- 
ulin isolated in the reactive lipoprotein- $\gamma$-globulin complex could be attributed to nonspecific contamination, whereas all of the $\gamma$-globulin isolated with the unreactive lipoprotein could be attributed to nonspecific contamination. These results are incompatible with a soluble antigen-antibody complex of $\gamma$-globulin and the unreactive $\mathrm{d}<1.063$ lipoprotein.

The possibility was examined as to whether large amounts of conjugated bile acids, or other serum factors which accumulate after obstruction, could interfere with the interaction of lipoprotein and antiserum. In one experiment, serum containing $81.4 \%$ unreactive lipoprotein was fractionated by gel-filtration on Sephadex G-200 in an isotonic, buffered medium. The lipoprotein fraction obtained in such a procedure is free of serum components with the exception of macroglobulins. This fraction was concentrated and assayed for unreactive lipoprotein: $82.2 \%$ was unreactive. Furthermore, it was shown by double diffusion in gel that highly purified preparations of the unreactive lipoprotein did not exhibit reactivity to antisera prepared against $\mathrm{d}<$ 1.063 lipoproteins (Fig. 4).

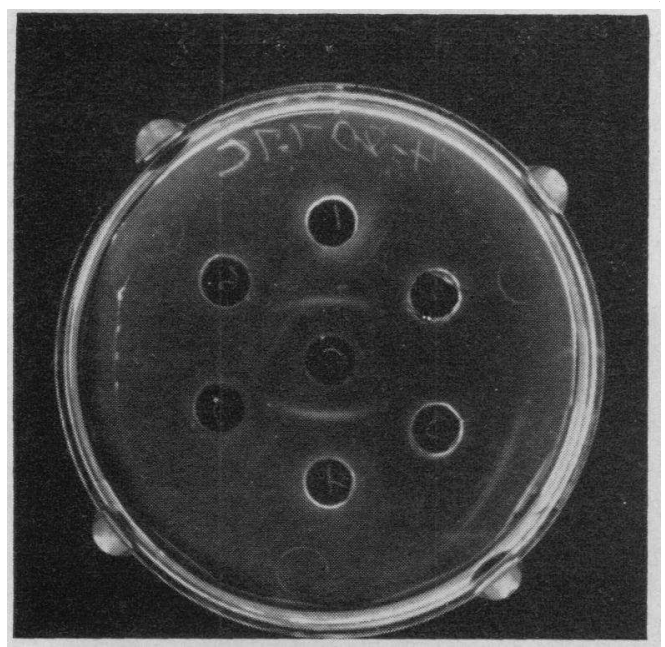

Fig. 4. Double diffusion of OLP in AgARose GEL. In the center well is a purified preparation of OLP from patient LB with biliary atresia. The peripheral wells are numbered clockwise from the top. In these wells are (1) rabbit antiserum to OLP absorbed with $\mathrm{d}>1.063$ lipoproteins, (2) rabbit anti- $\beta$-lipoprotein antiserum (Behringwerke), (3) goat anti- $\beta$-lipoprotein antiserum (Hyland), (4) same as 1 , (5) rabbit anti- $\alpha_{1}$-lipoprotein antiserum (Behringwerke), (6) rabbit anti-goat, $\gamma$-globulin antiserum (Hyland).
TABLE III

A mino acid composition of lipoprotein fractions from subjects with obstructive jaundice (OLP) and from normal pooled sera

\begin{tabular}{|c|c|c|c|c|}
\hline & OLP* & $\mathrm{d}<1.006 \ddagger$ & $\begin{array}{c}\text { d 1.019- } \\
1.063 \ddagger\end{array}$ & $\begin{array}{l}\text { d 1.063- } \\
1.21 \ddagger\end{array}$ \\
\hline & \multicolumn{4}{|c|}{ residues/1000\$ } \\
\hline Aspartic & 96.9 & 102.9 & 106.1 & 74.1 \\
\hline Threonine & 55.0 & 58.2 & 62.9 & 43.9 \\
\hline Serine & 89.8 & 97.3 & 85.9 & 56.0 \\
\hline Glutamic & 144.1 & 153.9 & 120.8 & 184.0 \\
\hline Proline & 32.4 & 27.2 & 54.2 & 37.6 \\
\hline Glycine & 57.6 & 47.1 & 45.8 & 43.0 \\
\hline Alanine & 90.1 & 90.0 & 67.3 & 68.4 \\
\hline Valine & 60.9 & 74.6 & 45.3 & 58.9 \\
\hline Isoleucine & 29.0 & 30.7 & 60.7 & 14.1 \\
\hline Leucine & 96.4 & 97.9 & 118.9 & 146.0 \\
\hline Tyrosine & 24.6 & 27.9 & 26.9 & 34.7 \\
\hline Phenylalanine & 45.2 & 43.9 & 56.5 & 40.2 \\
\hline Lysine & 96.1 & 81.3 & 85.2 & 115.6 \\
\hline Histidine & 15.3 & 16.9 & 22.8 & 18.1 \\
\hline Arginine & 58.9 & 39.8 & 50.5 & 55.7 \\
\hline
\end{tabular}

* Mean of duplicate analyses on three separate lipoprotein preparations.

$\ddagger$ Mean of duplicate analyses on two separate lipoprotein preparations.

§ Uncorrected for sulfur-containing amino acids.

Since it has been shown in our laboratory (unpublished observations) that $\mathrm{d}<1.063$ lipoproteins from rats with obstructive jaundice may contain considerable amounts of conjugated bile acids, a second experiment was performed in order to see if these materials could alter the reactivity of lipoprotein in normal serum. Accordingly, serum from a normal subject was mixed with sufficient sodium taurocholate to raise the level of conjugated bile acids by $80 \mathrm{mg} / 100 \mathrm{ml}$. After $15 \mathrm{~min}$ at room temperature, an assay for unreactive lipoprotein was performed that yielded a value of $1.5 \%$. This is not significantly different from that routinely obtained on normal sera. It is concluded that extraneous serum factors are unlikely to account for the altered immunoreactivity of the lipoprotein in these sera, although we cannot exclude more subtle effects of unknown factors in vivo.

The unusual lipid composition of the unreactive lipoproteins suggested that alterations in peptide conformation related to the lipid composition might account for nonreactivity by rendering the antigenic site inaccessible. To ascertain a possible relationship of the apoprotein of the unreactive lipoprotein to those present in reactive lipoproteins, we performed amino acid analyses of lipoprotein fractions (Table III). Unreactive d 1.0061.063 lipoproteins were prepared by first remov- 


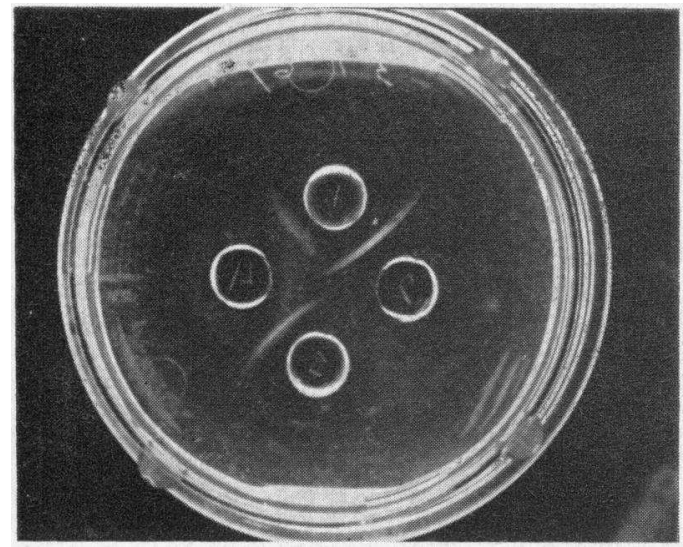

Fig. 5. Double diffusion of OLP ANd NORMAL SERUM IN AGAROSE GEL. In the top well is serum from a normal donor; in the right well is goat anti- $\beta$-lipoprotein antiserum (Hyland); in the bottom well a purified preparation of OLP from patient ARL with extrahepatic obstruction due to carcinoma; and in the left well antiserum to the OLP which is in the bottom well. This was absorbed with the $\mathrm{d}>1.063$ fraction.

ing the $\mathrm{d}<1.006$ lipoproteins by ultracentrifugation at $d 1.006$ and subjecting the $d>1.006$ proteins to immunoprecipitation, followed by mepesulfate precipitation ( 4 times) and then ultracentrifugation at $\mathrm{d} 1.063$. Three such preparations were analyzed in duplicate (Table III, column 1).

The results can be summarized as follows: the values for normal lipoproteins (Table III, columns 2-4) agree reasonably well with those reported by other workers (26-29). The amino acids that are most helpful in distinguishing the three major lipoprotein classes (as discussed below) are aspartic, glutamic, isoleucine, and leucine. When the data for the OLP are compared with those obtained from normal lipoproteins it can be seen that the amino acid composition most nearly resembles that of the $d<1.006$ lipoproteins. These data are compatible with the hypothesis that the OLP contains an apoprotein similar to that present in $\mathrm{d}<1.006$ lipoproteins. The data do not suggest a relationship to the $\mathrm{d} 1.063-1.21$ apoproteins.

If the determinant present in normal $\mathrm{d}<1.063$ lipoproteins is absent from the OLP it is conceivable that a different determinant is present. To test this possibility, rabbits were immunized with the OLP. The harvested antisera were absorbed with normal $\mathrm{d}>1.063$ serum proteins and double diffusion studies in gel were performed (Figs. 4 and 5). These antisera reacted strongly with the OLP originally prepared for immunization (Fig. 5) and with freshly prepared OLP (Fig. 4). It should be noted that antisera to the d 1.063-1.21 and $d<1.063$ determinants do not react with our most purified preparations of OLP (Fig. 4). Removal of the normal $\mathrm{d}<1.063$ lipoproteins from sera containing OLP by immunoprecipitation does not diminish the reaction of the OLP with its specific antiserum. The antiserum to OLP reacts weakly or variably with sera from normal subjects (Fig. 5). When normal sera are fractionated at $\mathrm{d} 1.006$, the antiserum to normal $\mathrm{d}<1.063$ lipoproteins reacts with both the

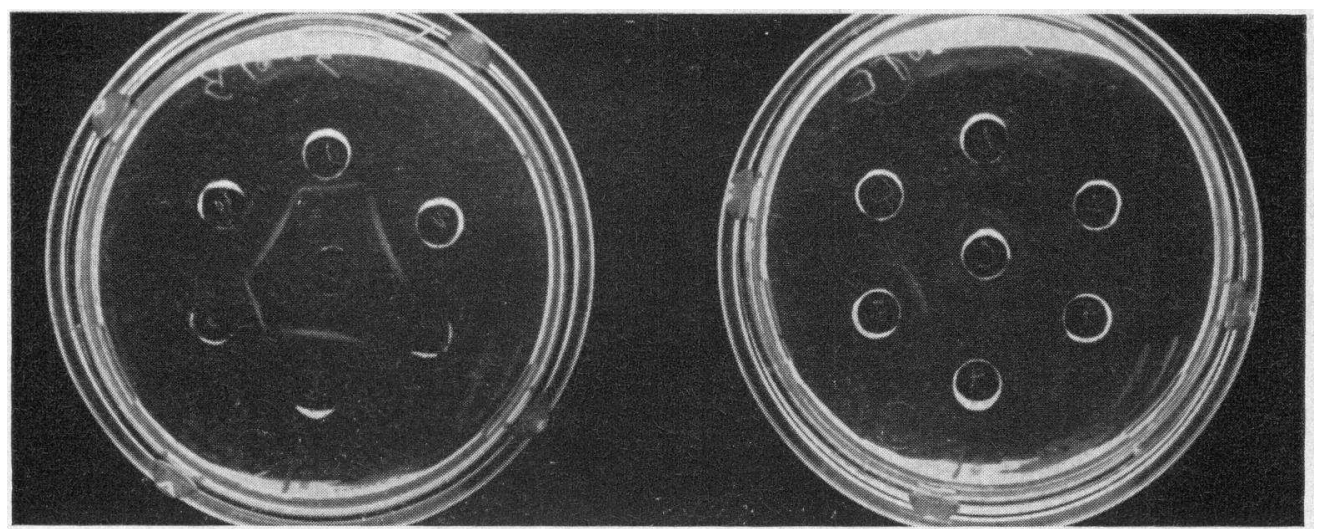

Fig. 6. Comparison of reactivity of antisera to nozmal $\mathrm{d}<1.063$ Lipoproteins and OLP. In the center well on the left is goat antiserum to normal $d<1.063$ lipoproteins. In the center well on the right is rabbit antiserum to OLP absorbed with the $d>1.063$ proteins. In the peripheral wells, numbered as in Fig. 4, are the $d<1.006$ lipoprotein fractions from three normal donors in wells 1,3 , and 5 , respectively, and the corresponding $d>1.006$ lipoprotein fractions in wells 2,4 , and 6 . 
$\mathrm{d}<1.006$ and $\mathrm{d}>1.006$ fractions, whereas, the anti-OLP does not react with the $d>1.006$ fraction, but does react to a variable degree with the $\mathrm{d}<1.006$ fraction (Fig. 6).

Thus, it appears that the OLP contains an antigenic determinant distinct from that found in normal d 1.006-1.063 lipoproteins, but common to one present in some $\mathrm{d}<1.006$ fractions prepared from normal serum.

\section{Discussion}

The extreme abnormalities of serum lipids in obstructive liver disease attracted the attention of early workers interested in lipid-protein complexes. Using electrophoretic techniques, Kunkel and Ahrens (30) studied eight cases of primary biliary cirrhosis while Sterling and Ricketts (31) studied 10 cases of biliary cirrhosis secondary to demonstrable extrahepatic obstruction. Both studies demonstrated that sera with elevated lipid levels from patients with biliary cirrhosis showed marked increases of $\beta$-globulin proportional to the elevation of lipids. Fractionation of serum lipoproteins in a large series of subjects with liver disease was first reported by Eder et al. (2) using Cohn fractionation. They found that patients with either biliary cirrhosis or extrahepatic obstruction displayed high levels of lipoprotein in Cohn fraction IV $+\mathrm{V}+\mathrm{VI}$. This lipoprotein was found to migrate electrophoretically as a $\beta$-globulin and to have a $d<1.063$. However, since lipoproteins of this density are not customarily found in fraction $\mathrm{IV}+\mathrm{V}+\mathrm{VI}$ but in fraction I + III, it was emphasized that this must be an abnormal lipoprotein with properties (solubility) which varied considerably from normal. Lipid analyses showed that in contrast to normally occurring $d<1.063$ lipoproteins, virtually all of the cholesterol in this lipoprotein fraction was in the free form and that the cholesterol-phospholipid ratio was low (0.4-0.5).

Isolation of this abnormal low-density lipoprotein was achieved from the serum of a single patient with primary biliary cirrhosis by Russ et al. (4) who used a combination of Cohn fractionation and ultracentrifugation. This lipoprotein had an average hydrated density of 1.041-1.042 and lipid analyses confirmed the earlier observations of Eder et al. (2). The protein content was $2 \%$, an unexpectedly low value for a lipoprotein of this density. Immunochemical studies were performed by Levine et al. (32). They failed to demonstrate a precipitin reaction between the abnormal lipoproteins and an antiserum known to react with all low-density lipoproteins from normal sera. The lipoprotein studied by these investigators thus appears to be the same or similar to the immunologically unreactive lipoprotein reported in this present study. It is emphasized, however, that the unreactive $d<1.063$ lipoprotein is not unique to biliary cirrhosis but is also found in patients with extrahepatic biliary obstruction.

In addition to the high concentration of the unreactive lipoproteins present in patients with obstructive jaundice, we found a normal concentration of immunologically reactive $d<1.063$ lipoproteins. This is consistent with earlier studies $(2,4)$. All of the studies cited indicate that under these circumstances $\alpha$-lipoproteins are diminished or absent as judged by electrophoresis on paper (2), starch (33), gel (the current study), or by ultracentrifugation $(2,3)$.

The lack of esterification of the cholesterol in the abnormal lipoprotein in the presence of significant cholesterol esterification of other lipoprotein fractions is of singular interest. Since the work of Thannhauser and Schaber $40 \mathrm{yr}$ ago, a decrease in serum cholesterol esters has been viewed as a sign of hepatic damage, per se (34). This view had been challenged earlier by Eder et al. (2). First, it must be emphasized that with obstruction the relative decrease of cholesterol esters is due, not to an absolute fall in cholesterol esters, but to a marked increase of free cholesterol. Furthermore, this increase of free cholesterol is limited almost wholly to a single lipoprotein fraction and, as has been shown experimentally in rats, this increase precedes demonstrable damage to hepatic parenchyma (35). Second, recent work indicates that the liver is not the sole source of plasma cholesterol ester (36-38), but that considerable esterification of lipoprotein cholesterol may occur in plasma due to the activity of a plasma enzyme, acyl transferase. Of particular relevance is the observation that acyl transferase is inhibited by sodium taurocholate (37). However, complete inhibition requires levels ( 5 moles/liter) far in excess of any we have measured in plasma.

We have suggested the following possibilities for the inability of antiserum to normal $d<1.063$ 
lipoproteins to precipitate the abnormal lipoprotein: (a) reaction between antigen and antibody occurs with formation of a soluble complex rather than of a precipitate; $(b)$ the presence of a serum factor interferes with the antigen-antibody reaction; $(c)$ the structure of the lipoprotein is altered so that, although the antigenic site is present, it is inaccessible to the antibody; and $(d)$ the apoprotein or some portion of the peptide differs sufficiently from the normal $d<1.063$ apoprotein as to change its antigenic specificity. From our studies utilizing labeled $\gamma$-globulin (Table III), it seems unlikely that a soluble antigenantibody complex is formed. Nor could we find evidence for the presence of serum factors extraneous to the lipoprotein itself that would interfere with the immune reaction.

It is certainly possible that the altered lipid composition of the OLP could change its immunologic reactivity, but as yet no data are available relative to this possibility.

The apoprotein in OLP could differ from that normally found in $\mathrm{d}$ 1.006-1.063 lipoproteins by virtue of $(a)$ the presence of an apoprotein normally found in other lipoprotein classes, or $(b)$ the appearance of an apoprotein not normally present in serum, or present only in small amounts. DeLalla et al. (39) found that a $d<1.063$ lipoprotein with $\beta$-mobility by electrophoresis reacted with an antiserum to high-density lipoproteins. This observation could be considered to be inconclusive because, as the authors note, the "antiserum used in this study was prepared against an aged lipoprotein in which alteration presumably had already occurred." It should be noted that we did not get a purified preparation of OLP to react with antiserum to $\alpha$-lipoprotein (Fig. 4) nor antiserum to OLP to react with serum from which only $\mathrm{d}<1.006$ lipoproteins had been removed (Fig. 6).

We have attempted to determine the nature of the apoprotein of OLP by $(a)$ amino acid analysis as a first step in the chemical characterization of the peptide and $(b)$ further study of the immunologic characteristics of OLP. In order to carry out these studies it is, of course, necessary to have "pure lipoproteins." This has been achieved with normal lipoproteins by a number of workers whose methods utilized repeated polyanion precipitation and ultracentrifugation (28,
40), to give "pure" fractions so characterized by immunochemical methods and by analytical ultracentrifugation. The lipoproteins prepared by the procedure utilizing immunoprecipitation in this study undoubtedly were contaminated with $\gamma$-globulin. This was demonstrated in the studies where labeled globulin was added and also by immunodiffusion (Fig. 4). However, even in studies of normal lipoproteins by Avigan et al. (41) and Roheim et al. (42), it was shown that when contamination was looked for by sensitive methods, absolute purity could not be obtained.

The $\mathrm{d}$ 1.063-1.21 and $\mathrm{d}$ 1.006-1.063 lipoproteins have distinctly different amino acid compositions (26-29). The $d<1.006$ and $d$ 1.006-1.063 lipoproteins, although differing in some respects, have a somewhat similar amino acid composition (27). The amino acids which are most likely to distinguish the major lipoprotein classes and which are least likely to be influenced by technical factors related to hydrolysis and chromatography are aspartic, glutamic, isoleucine, and leucine (28). When the amino acid composition of OLP is compared with that of lipoproteins from normal sera, it is apparent that the OLP is most similar to the $\mathrm{d}<1.006$ lipoproteins and unlike the $\mathrm{d}$ 1.063-1.21 lipoproteins. That OLP contains a mixture of d 1.063-1.21 and d 1.006-1.063 apoproteins seems unlikely, especially so because of their composition in respect to leucine, alanine, and serine. It should be emphasized that these studies represent only the beginning of the study of the chemical nature of the protein.

Consistent with the observation that the amino acid composition of OLP resembles that of normal $\mathrm{d}<1.006$ lipoproteins is the finding that antibody to OLP can react with normal $d<1.006$ lipoproteins. It is interesting to speculate on the relationship between this reaction and the studies of immunologic characteristics of the $d<1.006$ lipoproteins by other workers. Gustafson et al. (43) and Levy et al. (44) have found that partially delipidated $\mathrm{d}<1.006$ lipoproteins react with antiserum to both $\mathrm{d} 1.006-1.063$ and $\mathrm{d} 1.063-1.21$ lipoproteins. However, Granda and Scanu (27) were unable to find reactivity to high-density lipoproteins, except with fractions, from hyperlipemic sera, that also contained albumin. In addition, Gustafson et al. found a third component which was designated apolipoprotein C. Further study 
is necessary to determine whether this determinant is present in the OLP. Conceivably, the OLP contains yet another peptide not present in normal plasma. Of this, Anfinsen (45) has pointed out, ". . . de novo production of lipoprotein of an entirely new species, both as regards the protein part and the lipid part of the molecule . . . seems highly unlikely, since it would imply a new protein synthetic mechanism and a genetic change in the control of protein synthesis."

\section{Note added by Editors}

Shortly after the submission of this manuscript Dr. Switzer died, on 4 June 1967, as the result of an automobile accident. His colleagues and his many friends deeply regret his untimely death.

\section{References}

1. Rothschild, M. A., and J. Felsen. 1919. The cholesterol content of the blood in various hepatic conditions. Arch. Internal Med. 24: 520.

2. Eder, H. A., E. M. Russ, R. A. Rees Pritchett, M. M. Wilber, and D. P. Barr. 1955. Protein-lipid relationships in human plasma: In biliary cirrhosis, obstructive jaundice and acute hepatitis. J. Clin. Invest. 34 : 1147.

3. Furman, R. H., and L. L. Conrad. 1957. Ultracentrifugal characterization of the lipoprotein spectrum in obstructive jaundice: Studies of serum lipid relationships in intra- and extra-hepatic biliary obstruction. J. Clin. Invest. 36: 713.

4. Russ, E. M., J. Raymunt, and D. P. Barr. 1956. Lipoproteins in primary biliary cirrhosis. J. Clin. Invest. $35: 133$.

5. Havel, R. J., H. A. Eder, and J. H. Bragdon. 1955. The distribution and chemical composition of ultracentrifugally separated lipoproteins in human serum. J. Clin. Invest. $34: 1345$.

6. Burstein, M., and J. Samaille. 1957. Sur la précipitation sélective des $\beta$-lipoprotéines du sérum par l'héparine et les héparinoìdes de synthèse en presence du $\mathrm{Cl}_{2} \mathrm{Ca}$. J. Physiol. (Paris). $49: 83$.

7. Burstein, M., and J. Samaille. 1958. Dosage des $\beta$-lipoproteines seriques après precipitation selective par l'héparine. Presse Med. 66: 974.

8. Kabat, A., and M. M. Mayer. 1961. Experimental Immunochemistry. Charles C Thomas, Publisher, Springfield.

9. Stastny, M., and J. Horejsi. 1961. Interaction of acridine dyes with blood plasma proteins. Clin. Chim. Acta. 6: 782.

10. Scheidegger, J. J. 1955. A micromethod of immunoelectrophoresis. Une microméthode de l'immunoelectrophoresis. Intern. Arch. Allergy Appl. Immunol. 7 : 103.

11. Burstein, M., and J. M. Fine. 1964. Sur la mobilité des lipoprotéines du sérum humain en gel d'agarose. Rev. Franc. Etudes Clin. Biol. 9: 420.
12. Pressman, D., and H. N. Eisen. 1950. The zone of localization of antibodies V. An attempt to saturate antibody-binding sites in mouse kidney. $J$. Immunol. 64 : 273.

13. Mangold, H. K. 1961. Thin-layer chromatography of lipids. J. Am. Oil Chemists. Soc. 38: 708.

14. Switzer, S., and H. A. Eder. 1965. Transport of lysolecithin by albumin in human and rat plasma. J. Lipid Res. 6: 506.

15. Porath, J. 1959. Fractionation of polypeptides and proteins on dextran gels. Clin. Chim. Acta. 4: 776.

16. Spackman, D. H., W. H. Stein, and S. Moore. 1958. Automatic recording apparatus for use in the chromatography of amino acids. Anal. Chem. 30: 1190.

17. Folch, J., M. Lees, and G. H. Sloane Stanley. 1957. A simple method for the isolation and purification of total lipids from animal tissues. J. Biol. Chem. 226: 497.

18. Beveridge, J. M. R., and S. E. Johnson. 1949. The determination of phospholipid phosphorus. Cancer Res. 27 : 159.

19. Van Handel, E. 1961. Suggested modifications of the microdetermination of triglycerides. Clin. Chim. 7: 249.

20. Carey, J. B. 1958. The serum trihydroxy-dihydroxy bile acid ratio in liver and biliary tract disease. J. Clin. Invest. $37: 1494$.

21. Lowry, O. H., N. J. Rosenbrough, A. L. Farr, and R. J. Randall. 1951. Protein measurement with the Folin phenol reagent. J. Biol. Chem. $193: 265$.

22. Abell, L. L., B. B. Levy, B. B. Brodie, and F. E. Kendall. 1952. A simplified method for the estimation of total cholesterol in serum and a demonstration of its specificity. J. Biol. Chem. 195 : 357.

23. Sperry, W. M., and M. Webb. 1950. A revision of the Sperry-Schoenheimer method for cholesterol determination. J. Biol. Chem. 187: 97.

24. Leffler, H. H. 1960. Method for cholesterol and cholesterol ester determination in serum. In Lipids and the Steroid Hormones in Clinical Medicine. F. W. Sunderman and F. W. Sunderman, Jr., editors. J. B. Lippincott Co., Philadelphia. 18.

25. Eder, H. A. 1957. The lipoproteins of human serum. Am. J. Med. 23: 269.

26. Scanu, A., and W. L. Hughes. 1962. Further characterization of the human serum $d$ 1.063-1.21, $\alpha_{1}$-lipoprotein. J. Clin. Invest. $41: 1681$.

27. Granda, J. L., and A. Scanu. 1966. Solubilization and properties of the apoproteins of the very lowand low-density lipoproteins of human serum. Biochemistry. 5: 3301.

28. Margolis, S., and R. G. Langdon. 1966. Studies of human serum $\boldsymbol{\beta}_{1}$-lipoprotein I. Amino acid composition. J. Biol. Chem. 241: 469.

29. Levy, R. S., and A. C. Lynch. 1962. Amino acid analysis of human serum lipoproteins. Federation Proc. 21 : 75. 
30. Kunkel, H. G., and E. H. Ahrens, Jr. 1949. The relationship between serum lipids and the electrophoretic pattern, with particular reference to patients with primary biliary cirrhosis. J. Clin. Invest. $28: 1575$.

31. Sterling, K., and W. E. Ricketts. 1949. Electrophoretic studies of the serum proteins in biliary cirrhosis. J. Clin. Invest. 28: 1469.

32. Levine, L., D. L. Kauffman, and R. K. Brown. 1955. The antigenic similarity of human low density lipoproteins. J. Exptl. Med. 102: 105.

33. Kunkel, H. G., and R. J. Slater. 1952. Lipoprotein patterns of serum obtained by zone electrophoresis. J. Clin. Invest. $31: 677$.

34. Thannhauser, S. J., and H. Schaber. 1926. Uber die Beziehungen des Gleichgewichtes Cholesterin und Cholesterinester im Blut und Serum zur Leberfunktion. Klin. Wochschr. $5: 252$.

35. Boyd, G. S., M. A. Eastwood, and N. Maclean. 1966. Bile acids in the rat: studies in experimental occlusion of the bile duct. J. Lipid Res. $7: 83$.

36. Goodman, D. S. 1965. Cholesterol ester metabolism. Physiol. Rev. 45 : 747.

37. Glomset, J. A., and J. L. Wright. 1964. Some properties of a cholesterol esterifying enzyme in human plasma. Bioch. Biophys. Acta. 89: 266.
38. Sperry, W. M. 1935. Cholesterol esterase in blood. J. Biol. Chem. 111 : 467.

39. DeLalla, L., L. Levine, and R. Brown. 1957. Immunologic studies of human high density lipoproteins. J. Exptl. Med. $106: 261$.

40. Levy, R. I., and D. S. Fredrickson. 1965. Heterogeneity of plasma high density lipoproteins. J. Clin. Invest. 44 : 426.

41. Avigan, J., H. A. Eder, and D. Steinberg. 1957. Metabolism of the protein moiety of rabbit serum lipoproteins. Proc. Soc. Exptl. Biol. Med. 95 : 429.

42. Roheim, P. S., L. Miller, and H. A. Eder. 1965 The formation of plasma lipoproteins from apoprotein in plasma. J. Biol. Chem. 240: 2994.

43. Gustafson, A., P. Alaupovic, and R. H. Furman. 1964. Studies of the composition and structure of serum lipoproteins: physical-chemical characterization of phospholipid protein residues obtained from very-low-density human serum lipoproteins. Bioch. Biophys. Acta. $84: 767$.

44. Levy, Robert I., R. S. Lees, and D. S. Fredrickson. 1966. The nature of pre-beta (very low density) lipoproteins. J. Clin. Invest. 45: 63.

45. Anfinsen, C. B. 1954. Symposium on atherosclerosis, 22-23 March 1954. Natl. Acad. Sci. Natl. Res. Council Pub. 247. 